\title{
Factors and Dimensions Influencing Risky and Cautious Decisions: A Study of Selected Kenyan Secondary School Disciplinary Panels
}

\author{
Peter J.O. Aloka \\ University of the western cape, South Africa \\ Olaniyi Bojuwoye \\ University of the western cape, South Africa
}

Doi:10.5901/mjss.2014.v5n10p393

\begin{abstract}
The study investigated selected factors influencing risky and cautious decisions on student behavior problems during disciplinary hearing. The study adopted mixed methods approach. The participants comprised 78 teacher-members of selected school disciplinary panels. Quantitative data was collected using the Modified Choice Dilemma Questionnaire while qualitative data was collected by using the interview protocol. Quantitative data was analyzed by inferential statistics while qualitative data was analyzed by thematic framework. The findings indicated that factors such as gender, age and school categories of panel members influenced risky and cautious disciplinary decisions. Moreover, other factors such as behaviour characteristics of the offender $(\beta=1.143)$, the type of the problem $(\beta=0.746)$, the effects of the problem on disciplinary tone of the school $(\beta=$ 0.655) also influenced disciplinary decisions. The study recommended that members of school disciplinary panels should be sensitized on their role of fostering positive and healthy behaviours in students. Moreover, there is need to give consideration to composition of broad based school disciplinary panels.
\end{abstract}

Keywords: factors, risky, cautious, decisions, secondary school, panel, behavior problems

\section{Introduction}

The management of students' behavior problems has been a core concern of Kenyan schools (Aloka, 2012). Teachers in the past responded to these problems by relying on reactive measures such as corporal punishments to address the behaviour problems (Marais \& Meier, 2010). The human right abuses associated with corporal punishments have serious obstacle to learning process and hence to the attainment of the school's educational objective, and the overall development of students. To this end, therefore, how best to respond to students' maladaptive behaviours have become a central concern of schools. In this regard, the Department of Education's (2011) suggestion of a way to respond to students' maladaptive behaviours is for the schools to develop behaviour policy which stipulates standard of behaviour expected of students at schools, including how the standard is to be achieved. This includes any disciplinary penalties for breaking the rules and rewards for good behaviours (Department of Education, 2011). The success of any educational system depends on a systematic effort of the school to address behaviour problems (Rembolt, 1994). Poulou (2005), states that, schools need to find effective ways of promoting students' welfare on one hand, and helping teachers to deal with students' emotional and behavioural difficulties, on the other hand. As a consequence, schools have to develop student behaviour management practices aimed at addressing students' behaviour problems by using positive or reinforcing interventions, counseling and support (Poulou, 2005 in Aloka \& Bojuwoye, 2013). Each kenyan school is mandated to constitute a disciplinary panel with terms of reference or goals of ensuring student behaviour development along with the student overall development objective of the school.

School Disciplinary Panels are used to address students' behavior problems in Kenyan schools (Aloka, 2012). The disciplinary panels are committees of small group of teachers set up to assist schools in the development of students' behaviours. The disciplinary panels are guided by the school's rules and policies on behaviour expectations of students. The disciplinary panels periodically meet on student disciplinary or problem behaviours with a view to addressing personal and environmental factors associated with the behaviours and constituting barriers to or preventing students from meeting school's expectations on behaviours. A school with disciplinary panel makes use of consensus decisions of a small group of teachers instead of that of individual decision of the school principal to manage student behaviours. The final disciplinary decisions meant to manage the behavior problems can either be risky or cautious. Risky or extreme 
decisions are those decisions on the behaviour of the student which could threaten the student's dignity, safety and fundamental rights (Joubert, de Waal \& Rossouw, 2004). These risky decisions can result due to group think (Boateng, 2012) which occurs when members only seek harmony among themselves ignoring better alternatives to address a disciplinary problem. The risky decisions may lead to adverse or negative actions of the school authorities which may not promote the positive growth and development of the students but actually could be detrimental. On the other hand, cautious decisions are decisions which take into consideration the student's dignity, safety and fundamental rights in any action to be taken against the misbehaving student. Cautious decisions take into consideration extraneous circumstances surrounding the misbehaviour and avoid acts which may prevent the positive growth and development of the student.

\section{Literature Review}

\subsection{Influence of age on risky and cautious decisions}

Age is an important factor in decision-making in a group, and it determines whether an individual will influence or will be influenced during a group discussion. According to Watanabe \& Shibutani (2010), the decision making processes among the older people are characterized by a lack of flexibility in learning and changing of decisions and have increased cautiousness in making decisions compared with the younger people. That is, older people tend to have strong personality, strong ego or are self- opinionated. These opinions were supported by Masuda, Sakagami and Hirota (1997), who argue that older people have been stereotyped as being cautious, and they escape from choosing risky or extreme options in decisions. These young people recognize their inexperience and are easily persuaded to change or are liberal in their view of situations; so they may want to change their decision during group discussion (Watanabe \& Shibutani, 2010). In the African traditional system, age is associated with wisdom. Older adults' behaviour in decision making is thus viewed as more reliable and skilled than that of younger adults. Thus in a group, like in school disciplinary panel, if the information provider is an older person, the tendency would probably be for the younger members to give in to the older members' opinions as a sign of respect. There are studies that have investigated decision making abilities of young people compared with adults, which indicate that young people make more risky decisions than adults (Levin, Hart, Weller \& Harshman, 2007). Mossière \& Dalby (2008) asserts that differing life experiences, confidence, cognitive processing, or views of the justice system may explain age differences in the shifts in decisions in a group process. Because of lack of maturity to follow through with conviction, younger group members are more likely to be more fluid in their decisions. In contrast, the older age groups chose a verdict with more confidence and they show consistency, which demonstrates their more crystallized, or solidified, view of the justice system. Chen \& $\mathrm{Ma}(2009)$ investigated the role of anticipated emotions in risky decisions of young and older adults and reported that, older adults' decisions were significantly influenced by anticipated positive emotions, while those of the younger adults" were associated by anticipated negative emotions.

\subsection{Dimensions of disciplinary decisions}

There are dimensions of student disciplinary problems on which school disciplinary panels make decisions. Jobert, et al, (2004), state that positive behaviour management at school has two very important goals, namely to ensure the safety of staff and students and to create an environment conducive to learning and teaching. On these bases, policies on students' behaviours in schools, therefore, stipulate behaviours that are acceptable and those that are not acceptable. According to the Department of Education (2011), a school's policy on student behaviours is first and foremost an indication that students are expected to live by rule-guided behaviours to enable them have respect for themselves and others and to live amicably with one another. Student behaviours that are disruptive or result to disciplinary problems significantly affect the fundamental rights to feel safe, to be treated with respect and to learn (Mabena \& Prinsloo, 2000). Policies on student behaviours in school are therefore, in effect, the reflections of the country's supreme laws protecting citizens against behaviours that could threaten the dignity, safety and fundamental rights of people (Jobert, et al, 2004). Students who misbehave tend to perform poorly in school, tend to be absent frequently from school, are often found to abuse or threaten their teacher and student misconducts adversely affect other students' safety, security and success in education (Moloi, 2002). To enforce school policies on behaviour and to ensure that the environment of the school is made conducive for teaching and learning, school policies on behaviour also contain indication of sanctions for student misbehaviours. Disciplinary procedure in school is essentially about positive behaviour management aimed at promoting appropriate behaviour, developing self-discipline and self-control in students (Squelch, 2000). To ensure that these goals are achieved, the Department of Education (2011) recommends that decisions of student disciplinary behaviours should 
be based on four aspects or dimensions which include:

The types of disruptive behaviour presented at the disciplinary hearing - (whether or not the behaviour is acceptable or not acceptable, mild or very serious mis-behaviour), as indicated in the school rules and regulations or policies on student behaviours; The general evaluation of the offending student in terms of the latter's pattern of behaviour over time - (whether or not a first or habitual offender, or offence made in error); The effect(s) of disruptive behaviour on a victim or victims - (whether or not harm, abuse or violation of rights of victim has been committed and there is need for redress); and, the effect of the disruptive behaviour on the disciplinary tone of the school - (whether or not disruptive behaviour constitute embarrassment to the school or likely to paint the school's image in rather very negative way. Schools, however, are often not rigidly adhering to the Department of Education (2011) sugestions. According to Bear, (2008) schools are often flexible in the manner in which they handle some problems and teachers' attitudes to disciplinary problems also affect decision making on student disciplinary problems. This study investigated decision making of the Kenyan secondary school disciplinary panels on the bases of the four dimensions identified.

\subsection{Influence of gender on risky and cautious decisions}

Literature also indicates that, gender is a factor that can influence decisions to be either risky or cautious. Karakowsky \& Elangovan (2001) examined male and female decision making under risk and uncertainty at both the individual and the group levels. The study involved 163 undergraduate students who responded to four decision-making scenarios individually and in groups of varying gender composition. The results suggested that relative to men, women do not fare well in mixed-gender contexts. Ohtsubo, Masuchi and Nakanishi (2002), also agree that females in the minority position in a group discussion comply with the majority faction more easily than males. Powers \& Reiser, (2005) however, explain that gender differences occur because men have more perceived social power than women; hence women tend to be more likely to conform to men than are men to women. Van Leijenhorst, Westenberg \& Crone, (2008) studied gender and age influences on risky decision making. The study tested whether the development of decision making under risk is related to changes in risk-estimation abilities. Participants $(N=93)$ between ages 8-30 participated in the study. The study found out that, at all ages, females were more risk-averse than males in their choice of decisions. Apesteguia, Azmat and Iriberris' (2011) study also reported similar findings that, during group decision making tasks, women are less aggressive while men are more aggressive in their strategies.

Previous studies only reported on the existence of the risky or cautious decisions among people in other settings but not among teachers in disciplinary panels. The significance of the study could be with regard to the utility to which the information as to the types of disciplinary decisions that could lead to appropriate management of students behavior problems. The findings would provide useful information to education and school authorities in Kenya on better ways of managing the interactions among panel members during disciplinary hearings to be more effective in enhancing the quality of decisions. Therefore, since the final risky and cautious disciplinary decisions have implications on the management of students' behavior problems, it was important to investigate the factors and dimensions influencing risky and cautious decisions among members of disciplinary panels.

The following null hypotheses were tested:

There are no statistically significant differences on the bases of gender, age, school categories in the final risky or cautious decisions by members of selected Kenyan secondary school disciplinary panels Factors such as the type of the disciplinary problem, behaviour characteristics of the offender, effects of disciplinary problem on the victim, and, effects of the problem on disciplinary tone of the school, are not responsible for the risky and cautious disciplinary hearing decisions among the members of the school disciplinary panels

\section{Research Methodology}

\subsection{Research design}

The study adopted a mixed methods design, a design in which the investigator collects and analyzes data, integrates the findings, and draws inferences using both qualitative and quantitative approaches in a single study or a program of inquiry (Tashakori \& Creswell, 2007). The mixed methods design particularly addresses the concerns of both the quantitative and the qualitative researchers by pointing out that all human inquiry involves imagination and interpretation, intentions and values but must also necessarily be grounded in empirical, embodied experience (Morgan, 2007). 


\subsection{Study participants}

The population for this study comprised secondary school teachers in Rongo District of Kenya. From the population of secondary school teachers are drawn school disciplinary panel members and therefore, teachers are the best informants for this study. For the quantitative sample, 78 teacher-members of the disciplinary panels in the 10 secondary schools were selected of whom forty five (45) were males and thirty three (33) were female teacher-members of the disciplinary panels. Moreover, twenty-one panel members in the 20 to 29 years old age group, twenty-eight panel members in the 30 39 years old age group, fourteen panel members in the 40-49 years old age group, and fifteen panel members in the 5059 years old age group. For the qualitative phase of the study, a sample size, (n) of ten (10) panel members was selected for interviews using the purposive sampling technique.

\subsection{Instruments}

The Modified Choice Dilemma Questionnaire (MCDQ) an instrument used for quantitative estimation of the changes in decisions from pre to post disciplinary hearing was used to collect quantitative data. The MDCQ is a self-administered questionnaire which can be used with participants aged eight years old to adult age (21 years and above). The Modified Choice Dilemma Questionnaire had options from where panel members were to indicate whether there were one in ten chances, three in ten chances, five in ten chances, seven in ten chances or nine in ten chances that the offender was indisciplined. For the current study, the internal reliability co-efficient estimate obtained for the Modified Choice Dilemma Questionnaire was 0.608 , which was considered to be adequate, because it is above the minimum value. On the other hand, qualitative data was collected using in-depth interviews which allowed the researcher to follow up ideas, to probe responses and investigate motives and feelings of the participants (Eliahoo, 2011).

\subsection{Data collection procedures}

Permission to collect data was first sought from University of the Western Cape Research Ethics Committee. After which, the researcher sought permission to collect data from Kenyan teachers from the Ministry of Education and the principals of the selected secondary schools. The researcher first made introductory visits to the selected secondary schools in Rongo district to seek permission from the school principals and to also make appointments with the panel members on their days when they would hold their disciplinary hearing meetings. All the ethical considerations were ensured before the participants agreed to participate in the study. The researcher then gave the MDCQ questionnaires to the panel members just before the disciplinary hearing began. The participants were then expected to indicate their pre-disciplinary hearing individual decisions about the behaviour problems presented and to respond on the dimensions. Then, later after the disciplinary hearing meetings, each participant was issued with fresh MDCQ questionnaires to indicate post disciplinary hearing group decisions. At the end of the disciplinary hearing meetings, the researcher interviewed panel members purposively selected for this purpose. The interview was done in a separate room where the participants were free to give their views. The importance of the second phase was to complement the information that was obtained by the questionnaires. A total of 10 panel members were interviewed, with a participant sampled from every school disciplinary panel selected. Each of the interview sessions lasted about 30 to 45 minutes, thereafter, the participants was given an opportunity to ask questions.

\subsection{Data analyses}

The quantitative analyses involved the use of inferential statistics. Data from the MDCQ were entered, coded, cleaned and analyzed by means of the Statistical Package in the Social Sciences (SPSS) version 21. The Probability level (or $P$ value) set for the test of hypothesis using the Paired Samples T - Tests was at the ninety five percent (95\%) level of confidence for two-tailed statistical tests. Thus if the $P$-value from the test results is smaller, then the results are significant. However, if the results indicate a $P$-value of greater than $0.05(P>0.05)$, then they are not significant. The statistical tests such as one way Analysis Of Variance (ANOVA) with Scheffe's Post Hoc Comparisons, Multivariate ANOVA with Scheffe's Post-Hoc Comparisons and Regression Analysis, were employed. The raw data produced from the ten tape-recorded interviews were transcribed and read thoroughly, to check for any incomplete, inconsistent or irrelevant data (Willig \& Stainton, 2008). The transcriptions were analyzed thematically using the process described by Terre Blanche \& Durrheim, (1999). Trustworthiness of the qualitative data was also ensured. 


\section{Findings and Discussions}

\subsection{Demographic information}

The demographic information includes the characteristics of participants such as age, school category, years of teaching experiences, and gender. For the purpose of this study, the biographic statistics were with regard to the participants' gender, age and school category. There were forty five (45) males and thirty three (33) female teacher-members of the disciplinary panels who participated in the study. Moreover, thirty nine (39) panel members were from the co-educational schools, twenty three (23) panel members from boys' only schools, and sixteen (16) panel members from girls' only schools, who participated in the study. Regarding age, there were twenty-one panel members in the 20 to 29 years old age group, twenty-eight panel members in the 30-39 years old age group, fourteen panel members in the 40-49 years old age group, and fifteen panel members in the 50-59 years old age group, who participated in the study.

\subsection{Findings on the differences in risky and cautious decisions on the basis of gender}

The following null hypothesis was tested:

There are no statistically significant differences on the bases of gender, age, school categories in the final risky or cautious decisions by members of selected Kenyan secondary school disciplinary panels

To test whether there were statistically significant differences in the risky and cautious disciplinary hearing decisions between the male and female respondents, a one way Analysis of Variance (ANOVA) was performed on the scores. The one way ANOVA statistical test was performed to test this hypothesis at the $95 \%$ level of confidence. The summary results of the one way ANOVA are presented in Table 1:

Table 1: ANOVA results of the risky and cautious decisions on the basis of gender

\begin{tabular}{|c|c|c|c|c|c|}
\hline & Sum of Squares & Df & Mean Square & F & Sig. \\
\hline Between groups & 437.91 & 1 & 437.91 & 13.96 & $0.000^{*}$ \\
\hline Within groups & 2383.89 & 76 & 31.37 & & \\
\hline Total & 2821.80 & 77 & & & \\
\hline
\end{tabular}

${ }^{*} P<0.05$

From the ANOVA results presented in the Table 1 , the probability level of $P=0.000$ is less than $0.05(P<0.05)$. This is an indication that significant differences exist in the types of decisions between the male and female members of the selected Kenyan Secondary School disciplinary panels. Therefore, the null hypothesis which stated that, there are there are no statistically significant differences on the bases of gender in the final risky or cautious decisions by members of selected Kenyan secondary school disciplinary panels has been rejected.

\subsection{Findings on Risky and Cautious disciplinary decisions by School categories}

The following null hypothesis was tested:

There are no statistically significant differences on the bases of school categories in the final risky or cautious decisions by members of selected Kenyan secondary school disciplinary panels

The decisions of the panels of the three school categories were compared using the MANOVA statistical test and the results are presented in Table 2 . 
Table 2: The MANOVA results of the significance in the risky and cautious decisions among disciplinary panel members of the three school categories

\begin{tabular}{|c|c|c|c|c|c|c|}
\hline \multicolumn{2}{|c|}{ Effect } & value & F & Hypothesis df & Error df & sig \\
\hline \multirow{4}{*}{ School category } & Pillai's Trace & 0.214 & 2.18 & 8.00 & 146.00 & 0.32 \\
\cline { 2 - 7 } & Wilk's Lambda & $\mathbf{0 . 7 9 3}$ & $\mathbf{2 . 2 0}$ & $\mathbf{8 . 0 0}$ & 144.00 & $\mathbf{0 . 3 0}$ \\
\cline { 2 - 7 } & Hotelling's Trace & 0.251 & 2.22 & 8.00 & 142.00 & 0.29 \\
\cline { 2 - 7 } & Roy's Largest Root & 0.206 & 3.75 & 4.00 & 73.00 & 0.18 \\
\hline
\end{tabular}

From the MANOVA test results in the Table 2, there are no statistically significant differences in the pre and post disciplinary hearing shifts in decisions among the disciplinary panels of the three categories of Kenyan secondary schools (Wilk's Lambda test : $[F(8,114)=2.20, P=0.30, P>0.05]$, hence the null hypothesis which stated that there are no statistically significant differences in the pre and post disciplinary hearing shifts in decisions among the disciplinary panels of the three categories of Kenyan secondary schools, has been accepted. This means that the type of decisions of the panels of one category of school was not significantly different from any of the other category of schools' disciplinary panels. That is, school categories were not of any significant factor in the types of decisions by members of the selected Kenyan secondary school disciplinary panels. Since different schools view disciplinary problems differently resulting to differences in shifts in their decisions, it was therefore necessary to make a follow up on this significant result to determine where the differences occurred (or which category of schools was responsible for the difference) and this was done using the Scheffe's Post Hoc Multiple Comparisons test. The Scheffe's Post Hoc test compared the estimated differences in the pre and post disciplinary hearing shifts in decisions among the disciplinary panels of the three categories of schools on the factor of the effect of the problem on the disciplinary tone of the school. The Scheffe's Post Hoc Multiple Comparison results are presented in the Table 3.

Table 3: Scheffe's Post Hoc results on differences in risky and cautious decisions on the basis of school categories

\begin{tabular}{|c|c|c|c|c|c|}
\hline Factor & (I)School category & (J)School category & $\begin{array}{l}\text { Mean differences in shifts in decisions } \\
\text { (I-J) }\end{array}$ & Std. Error & Sig. \\
\hline \multirow{6}{*}{ School category } & \multirow{2}{*}{ Boys' only } & Co-educational & $1.50^{\star}$ & 1.241 & $0.000^{*}$ \\
\hline & & Girls' only & 0.52 & 1.312 & 0.297 \\
\hline & \multirow{2}{*}{ Co-educational } & Boys only & $1.50^{\star}$ & 1.241 & $0.000^{*}$ \\
\hline & & Girls' only & $2.02^{*}$ & 1.406 & $0.000^{*}$ \\
\hline & \multirow{2}{*}{ Girls' only } & Boys' only & 0.52 & 1.312 & 0.297 \\
\hline & & Co-educational & $2.02^{*}$ & 1.406 & $0.000^{*}$ \\
\hline
\end{tabular}

${ }^{*} \mathrm{P}<0.05$

The Scheffe's Post Hoc test results in the Table 3 indicate that differences in the types of decisions were only observed when co-educational schools' panel decisions were compared with those of all single-sex schools (boys' only or girls' only) on the factor of the effects of the disciplinary behaviour on the disciplinary tone of the school. Generally, the results indicate that the disciplinary panels in the three categories of schools made different shifts in their pre and post disciplinary hearing decisions. This could be because of the differences in disciplinary problems treated or differences in the ways each category of schools' disciplinary panels viewed disciplinary problems in relation to school's images or disciplinary tones of the schools.

The finding of this study did not support the notion that categories of schools or school affiliation of members significantly influence the decisions of the panels except when it came to consideration with regard to schools' disciplinary tones. Co-educational schools seemed to differ significantly from the other two categories of schools (single-sex boys' only and girls' only schools). The differences could be in the nature of disciplinary or behaviour problems of students in the two categories of schools as compared with the Co-educational schools. Members of the two categories of the singlesex schools (boys only and girls only) tended to be more cautious in their decisions as compared with members of the coeducational school disciplinary panels who were more risky or extreme in their decisions. The tendency towards risky decisions by co-educational school panel members could be a reflection of over protective tendency of adolescents, especially female students who are seen as vulnerable to abuses related to their gender. Their risky decisions may also be to caution male adolescents prone to involving themselves in risky behaviours. Vulnerability to abuses be female gender may not be as pronounced when in all female schools as when with opposite gender as in co-educational 
schools. More cautious decisions in girls' only schools may also make the application of extreme measures to behaviour problems in that context to be counterproductive rather than reformative. In the boys' only schools, societies have tended to be more liberal about adolescent boys' behaviours and to allow them more freedom. Hill and Lynch (1983) assert that boys and girls are generally treated differently, with independence encouraged in male children and compliance in females. Explanation given for this tendency is that during adolescence, girls are perceived to be more vulnerable to all forms of abuse and mistreatment because of the nature and evolving characteristics of the female gender (Crouter, Manke \& McHale, 1995). This finding is also consistent with Bastick's (2000) study which found that coeducational schools most significantly lower adolescent males' anti-social behaviours, therefore, coeducational schools could help reduce socially disruptive and violent behaviours of both adolescent males and female students. Similarly, Donatelli \& Schnees' (2010) study also found that, from a disciplinary aspect, students in single-sex classes seem to have more appropriate behaviour than coeducational classes, and the conclusion was that, single-sex schools do provide students with a better and healthier educational experience because they experience few disciplinary problems as compared with the co-educational schools. The study found differences in decisions on the effects of student behaviour problems on school disciplinary tones among the three different categories of schools. The explanation offered for this by Hoy \& Sabos (1998) is that schools treat student disciplinary problems differently depending on the school climate and how the teachers uphold the rules regarding disciplinary problems. Welsh (2000) also asserts that, schools differ considerably in the clarity of school rules and in the degree to which students have any influence on school policies, and that, schools are not at all identical in the rules, procedures, norms, and practices that make up school climate. The unique characteristics of each institution will be brought to bear on the nature of the services provided to meet the needs of the students. School climate generally offers significant potential for enhancing both the understanding and the prevention of student behavior problems as these affect how panel members make decisions regarding disciplinary or behaviour problem of students. It is important to indicate here that most of these findings that do not exist in previous studies within the Kenyan context, and they bring new knowledge about the effects of student behaviour problems on disciplinary tone of the school.

\subsection{Findings on the differences in risky and cautious decisions on the basis of age}

The following null hypothesis was tested:

There are no statistically significant differences on the bases of age, in the final risky or cautious decisions by members of selected Kenyan secondary school disciplinary panels

The Multivariate Analysis of Variance (MANOVA) statistical test was performed to test whether the estimated mean differences in the pre and post disciplinary hearing decisions, on the basis of the age groups, were significant. The MANOVA test results involve four commonly used multivariate tests namely the Pillai's trace test, Wilk's lambda test, Hotelling's test, and Roy's largest root test all of which may give different results when used on the same set of data, although the resulting conclusion from each is often the same (Stevens, 1992). However, the Wilk's lambda test is the most preferred, because it is the strongest of the four multivariate tests (Howell, 2002). The MANOVA results are presented in Table 4:

Table 4: MANOVA results of the differences in risky and cautious decisions on the basis of age groups

\begin{tabular}{|l|c|c|c|c|c|c|}
\hline \multicolumn{2}{|c|}{ Effect } & value & $F$ & Hypothesis df & Error df & sig \\
\hline \multirow{4}{*}{ Age groups of the panel members } & Pillai's Trace & 0.718 & 5.738 & 12.00 & 219.00 & $0.000^{\star}$ \\
\cline { 2 - 8 } & Wilk's Lambda & 0.360 & 7.400 & 12.00 & 188.00 & $0.000^{*}$ \\
\cline { 2 - 8 } & Hotelling's Trace & 1.570 & 9.117 & 12.00 & 209.00 & $0.000^{\star}$ \\
\cline { 2 - 8 } & Roy's Largest Root & 1.247 & 2.605 & 4.00 & 73.00 & $0.000^{\star}$ \\
\hline
\end{tabular}

From the MANOVA results in the Table 4, there are significant differences in the types of decisions among the members of selected school disciplinary panels on the basis of the age groups (Wilk's Lambda $(\lambda)$ test : $F(12,188)=7.40, P=$ $0.000, P<0.05)$. Hence, the null hypothesis which stated that there are no statistically significant differences, in the shifts from pre to post disciplinary hearing decisions, on the basis of the age groups of members of the disciplinary panels of selected secondary schools has been rejected. This means that there are differences in the shifts from pre to post disciplinary hearing decisions by members of the four age groups. Further data analysis was carried out to locate exactly where the differences lie. To do this, the Scheffe's Post Hoc Multiple Comparisons test was used for the analysis. The 
Table 3 presents the results of this Post Hoc test.

Table 5: Scheffe's Post Hoc results on differences in risky and cautious decisions on the basis of age groups

\begin{tabular}{|c|c|c|c|c|c|}
\hline Dependent variable & $\begin{array}{l}\text { (I)Age } \\
\text { group }\end{array}$ & (J) Age group & $\begin{array}{c}\text { Mean Differences in } \\
\text { shifts in decisions } \\
(1-J)\end{array}$ & Std. Error & Sig. \\
\hline \multirow{3}{*}{ The type of the disciplinary problem } & \multirow{3}{*}{$20-29$ years } & $30-39$ & 0.45 & 0.422 & 0.365 \\
\hline & & $40-49$ & 2.89 & 0.526 & $0.000^{*}$ \\
\hline & & $50-59$ & 3.10 & 0.722 & $0.000^{*}$ \\
\hline \multirow{3}{*}{ The behaviour characteristics of the offender } & \multirow{3}{*}{ 30-39 years } & $20-29$ & 1.72 & 0.263 & $0.019^{*}$ \\
\hline & & $40-49$ & 2.91 & 0.422 & $0.000^{*}$ \\
\hline & & $50-59$ & 1.70 & 0.652 & $0.023^{*}$ \\
\hline \multirow{3}{*}{$\begin{array}{l}\text { The effect of the problem on the disciplinary } \\
\text { tone of the school }\end{array}$} & \multirow{3}{*}{$40-49$ years } & $20-29$ & 1.66 & 0.563 & $0.035^{*}$ \\
\hline & & $30-39$ & 0.31 & 0.524 & 0.754 \\
\hline & & $50-59$ & 0.04 & 0.632 & 0.958 \\
\hline \multirow{3}{*}{ The effects of disciplinary problem on the victim } & \multirow{3}{*}{$50-59$ years } & $20-29$ & 4.59 & 0.410 & $0.000^{*}$ \\
\hline & & $30-39$ & 3.47 & 0.220 & $0.000^{*}$ \\
\hline & & $40-49$ & 1.01 & 0.426 & 0.065 \\
\hline
\end{tabular}

$* P<0.05$

The results as displayed in the Table 5 indicate that statistically significant differences exist among the disciplinary panel members of the four age groups regarding their risky and cautious decisions on all the four factors associated with disciplinary problems on which decisions were to be made. This means that age is a factor in the final risky and cautious decisions disciplinary hearing decisions. That is, age of the panel members could have influenced the differences in risky and cautious decisions. The results reveal that panel members of the age groups 40-49 years and 50-59 years made more cautious decisions, as compared to those in 20-29 and 30-39 years of age categories made risky decisions.

Shifts in decisions were also reported to happen when the information givers at disciplinary hearings were older and more experienced in teaching. Older and more experienced panel members are respected for their ages. Older members from their wealth of experiences in treating disciplinary problems in schools are often seen to provide disciplinary panels with opinions which often lead to members shifting from their pre-disciplinary hearing decisions to post-disciplinary hearing decisions. Younger and less experienced members of disciplinary panels seek opinions of more experienced members and the former are often persuaded to align themselves with the opinions on the latter. For instance, a boy accused of alcohol abuse and violent behaviour appeared before a school"s disciplinary hearing. Before the disciplinary hearing, the panel members were of the opinion that alcohol abuse and violent behaviours like fighting are unacceptable behaviours as these make the learning environment of the school unsafe, negatively impact on the image of the school as well as having negative effects on the health and academic development of students. The predisciplinary hearing decisions were therefore risky or extreme as panel members saw it fit to uphold the zero tolerance of such behaviour. However, during disciplinary hearing, information was provided to the effect that the student involved was a final year student. Older members of the panel felt that applying extreme sanction on the student could completely destroy him as he might not be able to write the final examination and graduate from the school. The older members persuaded the panel members to opt for a decision that will not lead the student jeopardizing the final examination, for example, holding on to his certificate until he has served punishment before releasing it. The student was also made to sign an undertaking to be of good behaviour while he was also reported to his parents. Considering this problem, the younger panel members reported that their decisions shifted when they were persuaded by the older members of the panel to adopt decisions that would not destroy the student but serve to reform him and give him another chance in life.

Two excerpts from interview transcripts reflecting the view of younger participants are as follows:

Prior to our meeting, I had decided that the boy should be suspended and even sit for his examinations from outside school. This was because the boy went out of school and consumed alcohol and engaged himself in fighting had committed serious offence according to the laid school rules and regulations. Later at the disciplinary hearing, I realized from senior members of the panel that suspending the boy would be detrimental to his whole future life because he could even abandon school and would even miss the final exams as well. I changed my decision and agreed with the more experienced panel members' opinions that suspending the boy may not contribute to reformation as was expected but that the student to be allowed to sit the final examinations and complete his schooling. My final decision supported those of the older members who suggested that the boy be sent for counseling and be supervised closely by the deputy 
principal, a decision which would enhance his future endeavours later after school.

In some other cases reported, the older and more experienced panel members did not easily shift from their predisciplinary hearing decisions during the panel deliberations, because they regarded the younger members as inaccurate and inexperienced. These senior members felt that they had to influence panel decisions because most of the younger members made risky decisions and that their opinions always proposed heavy sanctions instead of looking for ways of reforming the students. This finding is consistent with Schlottmann, (2000); Harbaugh, et al, (2002) and Levin, et al, (2007) who all found out that young people make more risky decisions than adults. Manning, et al, (2004) study also found that the younger judges were least sympathetic in their decisions (made more extreme or risky decisions) while the older judges were the most sympathetic in their decisions (made more cautious decisions). The younger and less experienced panel members made risky decisions, which means that, they were not as tolerant of the behaviour tendencies of students perceived to be problem behaviours or that they were probably more responsive to the dynamics of the panel group meetings. The older and more experienced members made cautious decisions, which mean that, they were probably more tolerant of the student behaviour tendencies perceived to be problem behaviours. The finding has implications for the composition of disciplinary panels, in that schools should ensure appropriate balance in the composition of disciplinary panels with members of both young and old, less experienced and more experienced teachers.

\subsection{Findings on dimensions associated with disciplinary problems on the risky and cautious decisions.}

The following null hypothesis was tested:

Factors such as the type of the disciplinary problem, behaviour characteristics of the offender, effects of disciplinary problem on the victim, and, effects of the problem on disciplinary tone of the school, are not responsible for the risky and cautious disciplinary hearing decisions among the members of the school disciplinary panels

The aim of the hypothesis was to ascertain if the four factors associated with disciplinary problems on which decisions were made influenced the risky and cautious decisions panel members' decisions during the disciplinary hearing meetings. A Multiple Regression Analysis was conducted to examine the effects of each of the factors on the risky and cautious decisions among the panel members. The multiple regression analysis is a statistical technique that allows us to predict an individual's score on one dependent component on the basis of several scores of other predictor (independent) factors (Brace, Kemp \& Snelger, 2003). The multiple regression analysis was interested in predicting the extent to which each of the predictor variables or the four factors associated with disciplinary problems.

To determine the extent of influence of each of the four factors on the risky and cautious decisions disciplinary decisions, the stepwise multiple regression analysis was done. The results of the Multiple Regression Analysis are presented in the Table 6.

Table 6: Stepwise Multiple Regression Results: Predicting the influence of the four factors on which decisions were made on the risky and cautious decisions

\begin{tabular}{|c|c|c|c|c|}
\hline Multiple Regression & 0.82 & & & \\
\hline R Squared $\left(\mathbf{R}^{2}\right)$ & 0.68 & & & \\
\hline R Squared (Adjusted R²) & 0.66 & & & \\
\hline \multirow[t]{2}{*}{ Standard error } & 3.49 & & & \\
\hline & & & & Sig. $P=0.029^{*}$ \\
\hline Variables in the equation & $\mathrm{B}$ & Standard error for $B$ & $\mathrm{t}$ & Sig. \\
\hline The type of the disciplinary problem & 1.14 & 0.23 & 4.92 & $0.000^{*}$ \\
\hline The behavior characteristics of the offender & 0.74 & 0.22 & 3.29 & $0.002^{*}$ \\
\hline The effect of the problem on disciplinary tone of the school & 0.65 & 0.23 & 2.85 & $0.035^{*}$ \\
\hline The effect of disciplinary problem on the victim & 0.42 & 0.23 & 1.85 & 0.067 \\
\hline
\end{tabular}

${ }^{*} \mathrm{P}<0.05$

The information presented in Table 6 presents the results of regression of four factors on the risky and cautious decisions of the panel members. The results indicate that only three factors associated with the disciplinary problems - the type of 
the disciplinary problem $(P=0.000, P<0.05)$, the behaviour characteristics of the offender $(P=0.002, P<0.05)$, and the effects of the problem on disciplinary tone of the school $(P=0.035, P<0.05)$ significantly influenced the the risky and cautious decisions. However, the effect of disciplinary problem on the victim $(P=0.067, P>0.05)$ was not significant in its influence on the the risky and cautious decisions. The results also indicate that the value of Adjusted $\mathrm{R}^{2}=0.668$. When the adjusted $\mathrm{R}^{2}$ value is expressed in percentage, it becomes $66.8 \%$ or approximately $67 \%$. This means that $67 \%$ of what explained the risky and cautious decisions can be accounted for by the four factors and the other $33 \%$ can be accounted for by other variables (factors that were not considered). However, if all the factors are entered into the equation, then this value would change. Therefore, the shifts in decisions from pre to post disciplinary hearing decisions can also be greatly attributed to the four factors associated with disciplinary problems, just as other factors. Moreover, it was necessary to account for each of the factors that were entered in the equation, to ascertain the extent to which each of them influenced the risky and cautious decisions. The results from the size of Beta values (B) indicated that the behaviour characteristics of the offender remained the most significant factor influencing the risky and cautious decisions among the panel members $(B=1.143)$, followed by the type of the problem $(\beta=0.746)$. The third was the effects of the problem on disciplinary tone of the school $(\beta=0.655)$, but the effects of disciplinary problem on the victim had little significance $(\beta=0.428)$, in its influence on the risky and cautious decisions among the panel members.

This notion is consistent with the Department of Education (2011) behaviour management policies, particularly the need to give students expectations of behaviour standards in school, as well as the need for building socially acceptable behaviours in students so that they can become better adults and good citizens, the need for ensuring that school environment is safe and secure for teaching and learning and finally, the need for projecting good image of an organization which one identifies with or belong to. Bear's, (2008) study found that, schools differ in the manner in which they handle the same problems, the teachers may have different attitude and some may be unwilling to actively participate in making very harsh decisions and this equally affects how their opinions would polarize in favour of negative decisions. Chang's (2009) study indicated that, in disciplinary panels where such factors are not considered in making decisions, members would overlook the use of proactive strategies to cope with student misbehaviour. Graham, et al, (2010) also confirm that, these four aspects associated with disciplinary problems lead to decisions that are proactive to ensure that offending students would thus be coached towards the desired behaviours. The conclusion that can be drawn from this study finding is that school disciplinary panels would be seen to be making good quality decisions when such decisions ensure safe and secure school environment for teaching and learning, when school students are seen to be assisted in displaying socially acceptable behaviours and when schools are seen as education agencies that the society can be confident in for promoting positive behaviour development in the students.

\section{Concluding Remarks}

Schools and school disciplinary panels have responsibility to assist students understand that people live by rule-guided behaviours, and for social harmony, that there are certain behaviours which are socially unacceptable. School Disciplinary Panels, therefore, exist to foster positive and healthy behaviours in students. By the decisions of school disciplinary panels, students are helped to develop healthy behaviours towards self, towards others and towards the school as a social organization, or organization which society have respect for, and confidence in, to provide safe and conducive environment for the promotion of positive development of all students. The study recommends that all teachers also need to be trained in student behaviour management in their teacher education programmes. The study recommends that there is need to give consideration to composition of broad based disciplinary panels. By broad base it is meant that members of a school disciplinary panel should reflect the demographic composition of all stakeholders. Thirdly, there is need for better education on behaviour management practices of schools. This is because a great deal of student behaviour problems can be avoided if students are adequately informed about their school's behaviour management practices.

One limitation of the study was that, the researcher tried to adapt the Modified Choice Dilemma Questionnaire to the Kenyan context and, no doubt, yielded valuable information for the study. However, a wholly Kenyan constructed instrument probably would have yielded different information and by so doing improve the findings of the study. The researcher checked on this by interviewing other senior teachers who were also members of the disciplinary panels and by so doing, believed that the effects of adopting a foreign constructed instrument for data collection would have been minimized. Future research could also look into the effects of cautious and risky decisions on behaviour of students who appear at disciplinary hearings. In conclusion, risky and cautious decisions seen in the disciplinary hearing process are much more than punishment but as incorporating positive behaviour development process. This way, school disciplinary panels play their important role of facilitating behavioural and moral development of students, or the development of the 
whole person' in each of the secondary school students. Disciplinary panels that are equipped to make good quality decisions would thus promote the students' development which includes emotional, cognitive, moral, social, and the behavioural competences.

\section{Acknowledgement}

The writing of this paper has been supported by the University of the Western Cape Writing Fellowship

\section{References}

Aloka, P.J.O. \& Bojuwoye, (2013).Gender, age and teaching experiences differences in decision-making behaviours of members of selected Kenyan secondary school disciplinary panels. Asian Social Science, Volume 9 (10), 43-55. doi:10.5539/ass.v9n10p43.

Aloka, P.J.O. (2012). Group polarization in decision making: a study of selected secondary school disciplinary panels in Rongo district of Kenya. Unpublished PhD thesis, Faculty of Education, University of the Western Cape, Cape Town, South Africa.

Apesteguia, J., Azmat, G., \& Iriberri, N. (2011). The impact of gender composition on team performance and decision-making: Management science, forthcoming.

Bastick, T. (2000). Differences between anti-social adolescent behaviour in single sex schools and co-educational schools in Jamaica. A paper presented at the Annual Meeting of the Society for Cross-Cultural Research (29th, New Orleans, LA, February 22-27, 2000).

Bear, G. G. (2008). Classroom discipline. In A. Thomas \& J. Grimes (Eds.), Best practices in school psychology: Vol. 5. Bethesda, MD: National Association of School Psychologists.

Boateng, W. (2012). Evaluating the efficacy of focus group discussion (FGD) in qualitative social research. International Journal of Business and Social Science, Volume, 3(7), 54-57.

Brace, N., Kemp, R., \& Snegler, R. (2003). SPSS for psychologists: A guide to data analysis: Using SPSS for windows (2nded). New York, NY: Palgrave MacMillan.

Chen, Y., \& Ma, X. (2009). Age differences in risky decisions: The role of anticipated emotions. Educational Gerontology, Volume,35 (7), 575-586.

Crouter, A. N, Manke, B. A., \& McHale, S. M. (1995). The family context of gender intensification in early adolescence. Child Development, 66(2), 317-329.

Department of Education, (2011). Ensuring good behaviour in schools. Retrieved November 20, 2011, from http://www.education.gov.uk/publications.

Donatelli, J., \& Schnee, E. 2010). Co-ed or single sex education: What's the difference?Retrieved August 2nd, 2010 from http://nyteachers.wordpress.com/coed-or-single-sex-educationwhat\%E2\%80\%99s-the-difference/.

Eliahoo, R. (2011). Dilemmas in measuring the impact of subject-specific mentoring on mentees" learners in the lifelong learning sector. Practitioner Research in Higher Education, 5 (1), 39-48.

Hanson, W. E., Creswell, J., Plano-Clark, V., \& Creswell, D. (2005). Mixed methods design in counseling psychology. Journal of Counseling Psychology, 52, 224-235.

Hill, J. P. \& Lynch, M.E. (1983). The intensification of gender-related role expectations during early adolescence. In J. Brooks-Gunn \& A Petersen (Eds.), Girls at puberty: Biological and psychological perspectives (pp. 201-228). New York: Plenum.

Joubbert, R., de Waal, E., \& Rossouw, J. P. (2004). Discipline: Impact on access to equal educational opportunities. Perspectives in Education, Volume 22(3), 77-87.

Karakowsky, L., \& Elangovan, A.R. (2001). Risky decision making in mixed-gender teams: Whose risk tolerance matters most? Small Group Research, Volume. 32, 94-111.

Levin, I. P., Hart, S. S., Weller, J. A., \& Harshman, L. A. (2007). Stability of choices in a risky decision making ask: A 3-year longitudinal study with children and adults. Journal of Behavioral Decision Making, 20, 241-252.

Levine, J. M., and R. L. Moreland, (1998). Small groups. In The handbook of social psychology. Fourth ed., (ed.) D.T. Gilbert, S.T. Fiske and G. Lindzey, vol. 2, McGraw-Hill, Boston, MA,pp. 415-469.

Mabena, M. Z., \& Prinsloo, E. (2000). Perceptions of discipline and ensuring discipline problems in secondary education. SA Journal of Education, 20(1), 34-41.

Marais, P., \& Meier, C. (2010). Disruptive behaviour in the Foundation Phase of schooling. South African Journal of Education, Volume, 30(1), 41-57.

Masuda, S., Sakagami, T., \& Hirota, S. (1997). Decision making be elderly people: Escape from choosing. Japanese Psychological Review, 40, 457-465.

Moloi, P. I. M. (2002). The role of the parents in discipline as an aspect of school safety. Unpublished Dissertation, Johannesburg: Rand Afrikaans University.

Morgan, D. L. (2007). Paradigms lost and pragmatism regained: Methodological. Mixed Methods Research, Volume 1(1), 3-7.

Mossiere, A., \&Dalby, J. T. (2008). The influence of gender and age on mock juror decision-making.Europe's Journal of Psychology, Volume, 2(8). Retrieved November 17th, 2011, from http://www.ejop.org/archives/2008/11/_the_influence.html.

Ohtsubo, Y., Masuchi, A., \& Nakanishi, D. (2002). Majority influence process in group judgment: Test of the social judgment scheme model in a group polarization context. Group Processes and Intergroup Relations, 5, 249-261.

Poulou, M. (2005). The prevention of emotional and behavioural difficulties in schools: Teachers" suggestions. Educational Psychology in Practice, Volume,21(1), 37-52.

Powers, R. S., \&Reiser, C. (2005). Gender and self-perceptions of social power. Behaviour and Personality 33(6), 553-568.

Remboldt, C. (1994). Solving violence problems in your school: Why a systemic approach is necessary. Minneapolis, MN: Johnson Institute.

Schlottmann, A. (2000). Children's judgments of gambles. Journal of Behavioral Decision Making, Volume, 13, 77-89.

Squelsh, J. M. (2000). Discipline. Pretoria: CELP.

Tashakkori, A., \& Creswell, J. W. (2007). The new era of mixed methods.London: Sage Publications.

Terre Blanche, M., \& Durreheim, K. (1999). Research in practice. Cape Town: UCT Press.

Van Leijenhorst L., Westenberg, P. M., \&Crone, E. A. (2008). A developmental study of risky decisions on the cake gambling task: Age and gender analyses of probability estimation and reward evaluation. Developmental Neuropsychology, Volume, 33 (2), 179-196.

Watanabe, S., \& Shibutani, H. (2010). Aging and decision making: Differences in susceptibility to the risky-choice framing effect between older and younger adults in Japan. The Japanese Psychological Research, Volume, 52(3), 163-174.

Willig, C., \& Stainton, R. (2008). Handbook of qualitative research in psychology. London: Sage Publications. 